\title{
The Teaching Model of Follow-up Writing after Reading in Senior High School English Based on Interactive Perspective
}

\author{
Fang Xia \\ Xindeng High School, Hangzhou 311400, Zhejiang, China \\ DOI: $10.32629 /$ JHER.V2I6.528
}

\begin{abstract}
With the continuous implementation of the new curriculum reform policy, new requirements have been put forward for the teaching mode reform of the majority of front-line teachers, and the teaching mode based on the perspective of interaction arises at the historic moment. According to the current actual teaching situation, there are some problems and deficiencies in the after-reading English writing class of senior high school. We need to take interactive teaching mode as the starting point to find a new teaching idea for enhancing the after-reading English writing ability of senior high school students.
\end{abstract}

Keywords: interactive perspective, senior high school English, follow-up writing after reading, teaching strategy

Currently, according to the basic requirements of the general high school English syllabus, the importance of reading after writing is given increasing top priority. However, from the practical point of view, there are still many problems in its teaching, which leads to the poor effect of students' follow-up after reading. Based on this, it is necessary to find feasible and effective application strategies based on the "interactive perspective", so as to provide guidance and reference for gradual improvement in students' thinking and ability of writing after reading, and comprehensive language application ability as a whole.

\section{Overview of relevant definitions}

\subsection{The connotation of the continuation after reading}

In current language teaching, the continuation of reading is a series of reading and writing, whose purpose is to cultivate students' comprehensive application skills of language. In the reflection phase in the process of teaching model, students are encouraged to carefully read the text and sort the context structure for in-depth analysis of key points of the text, and then put himself fully into the text context so that students can study purpose and sensations from the perspective of the authors, as a result, students are capable of the creation of the follow-up story. Therefore, the entire content can be ensured to be more reasonable and smooth, and text style. In general, reading follow-up has the characteristics of reading compound writing, which requires students to carry out "reading $\rightarrow$ reasoning $\rightarrow$ writing" training in a relatively open environment. In fact, it can be said that the development of students has experienced three processes, namely: understanding, creation and output. In a word, reading and writing after reading is very strict for students' reading and writing skills, but also need to gradually improve the level of story writing on the premise of "interactive awareness and ability".

\subsection{Connotation based on the interaction}

Conceptually, interaction denotes that a person is fully engaged in a certain activity or situation for deep perception and recognition. It can also be understood as a connection and influence between people influenced by specific media (such as language, social background, etc. ). In the teaching of follow-up writing after reading in high school, the feature of "interactive perspective" emphasizes the cultivation of students' creative ability. In other words, through continuous classroom activities, teachers and students can gradually improve the quality of classroom interaction by using verbal or non-verbal interaction modes, so as to achieve the purpose of text interaction, teacher-student interaction and student-student interaction.

That is to say, classroom based interaction is not aimed to give the dominant position of the teachers, rather students are encouraged for active participation. Besides, classroom interaction doesn't mean "cramming education" and "passive response" "interaction"on the pretext of so called "interaction" and "communication" by teachers. Instead, the content should be also diversified due to the variety of classroom interaction. 


\section{Problems in the teaching mode of writing after reading in senior High school}

\subsection{Failure of students in accurate analysis of the text structure}

In high school English classes, students are required to accurately analyze the text structure and carefully understand its style characteristics. However, from a practical point of view, certain students fail to make it during text reading, which will not only adversely affect the effect of follow-up after reading, but also cause certain restrictions on specific implementation strategies. Consequently, the advantages of follow-up after reading fails to be given full play. Generally, Generally, in the process of implementing "classroom interaction", some teachers identify "students' in-depth understanding of Chinese connotations in articles" as the key and difficult points in teaching, which generally takes a lot of time to introduce grammar knowledge related to it, it is contrary to the requirements of "text interaction" in "classroom interaction". According to the connotation of text interaction, it emphasizes that students should have a comprehensive understanding of the theme and idea of the creation of the article. However, during the explanation of the article, teachers usually do not pay attention to guide students to comprehensively analyze the style of the article, resulting in students unable to deeply understand the connotation of the text, which will inevitably limit the interaction of the text. In this case, students cannot accurately grasp the creative theme of the article and simply read and write in the way of "6. ", which is not conducive to the effective training and improvement of students' reading and writing ability. In addition, the traditional classroom teaching mode is too dull and boring, unable to maximize the enthusiasm of students to learn, resulting in low efficiency of classroom teaching.

\subsection{Lack of personalized follow-up instructions after reading}

In the follow-up cultivation of English reading in high school, some teachers are required to give personalized and targeted guidance and assistance to students to help them sort out the context structure and deeply analyze the text content. However, teachers fail to carry out targeted guidance, which result in serious problems in teachers' teaching, as obvious differences in ability of each student in reading and writing and interest in writing, as well the teaching mode of "instruction of one teachers for many students". Consequently, it gives rise to serious problems in teachers' teaching, such as going through formalities for formalities sake formalities, which will inevitably restrict the improvement of teaching quality.

\subsection{Lack of skills and methods of follow-up writing after reading among students}

Generally speaking, the factors affecting the improvement of high school students' ability to write after reading are very complex. For example, the lack of proficiency in training skills is one of the most critical factors. In practical teaching, many teachers ignore the importance of guidance and education, resulting in most students, especially those with weak reading and writing foundation, fail to obtain an ideal performance. In a sense, the influence of the exam-oriented education concept on the majority of teachers and students can not be underestimated, resulting in over attention to examination by the majority of teachers and students. Even under the influence of the new curriculum reform, teachers will introduce some writing methods related to writing and reading, but there are still great shortcomings in the practical training, which can not enhance students' flexible application ability.

\subsection{Weak consciousness of students in writing after reading}

For the continuation training of high school in English reading, teachers are required to guide students to form the corresponding thinking consciousness. Compared with the master of relevant skills, it is very important to cultivate students' learning consciousness, and there are certain resistance and difficulty. It can be seen from the research on the specific situation of reading after writing in senior high school that most students have show clear attitudes that reading after writing is not a very important learning task. Although some students think it is necessary, there is often blindness in actual learning and they do not know how to "carry it out". Compared with the training of reading and writing in English teaching, there is a great difference between reading and writing after reading. It cannot completely continue the traditional English reading and writing methods. If the majority of teachers do not attract high attention, it will inevitably affect the formation of students' thinking ability, resulting in students' weak consciousness of writing after reading, unable to maximize the enhancement of learning enthusiasm.

\section{The teaching mode of writing after reading English in senior high school based on the interactive perspective}

\subsection{Creation of reading teaching situation to guide students to understand text structure}

If students fail to have deep analysis of the text style and understanding of the structure of the text, it will cause resistance to the next writing. Therefore, in practical teaching, teachers must introduce scientific and effective teaching methods during 
the implementation of classroom interaction strategies, and try their best to solve the above problems. Generally speaking, a free reading atmosphere is created for students through in-depth reading of textbooks, and the relevant reading situation is set up to guide students to achieve "text communication" during text reading, so that they can accurately analyze the text style to pave the way for the next writing. For example, in the process of reading the article "Amazing People", students need to collect some pictures and videos related to the experience of explorer "Howard Carter" through the multimedia platform, so as to create a novel, curious and adventure-seeking reading environment for students. Based on this, it can help students understand the style of the article more deeply and master the main idea of the article. On the premise of students' accurate grasp, they can bring support and help for the subsequent writing, so that they can write efficiently.

\subsection{Implementation of hierarchical teaching mode to strengthen personalized guidance and education}

According to the requirements of the new curriculum standards, stratified teaching mode has been applied in the development of modern education. Therefore, from the perspective of interaction, teachers are required to implement hierarchical teaching mode to give personalized guidance and assistance to students' follow-up after reading, so as to gradually improve the quality of teaching. For example, in the process of reading the article "Law and Order", students should first solve their problems of recognition of new words so as to remove all kinds of reading barriers, and students should be stimulated to explore the text knowledge and connotation. Then, students should set different classroom reading tasks by carefully observing their learning situation. The hierarchical guidance can help some students with different basic knowledge and reading and writing ability to obtain hierarchical "text interaction" experience, which can lay a solid foundation for the follow-up after reading, and facilitate students to think about their own content and creation direction on this basis. In addition, in the process of helping students to complete a task, teachers need to carefully observe the students' actual performance. Besides, teachers should deeply communicate and exchange with students, accurately evaluate students' after-reading writing effect through high-quality "teacher-student interaction", and then give personalized guidance and inspiration to students based on their shortcomings and shortcomings, so as to promote students' after-reading writing ability to be constantly improved.

\subsection{Adoption of micro-lesson technology to guide students to master the method of follow-up after reading}

Under the influence of the teaching mode of follow-up after reading in senior high school based on the interactive perspective, teachers must implement scientific and effective teaching mode, guide students to master relevant skills and methods, and then promote students to flexibly apply them. For example, in-depth analysis of the method of follow-up after reading is carried out through micro-lesson technology to help students gradually master relevant skills and methods. Regarding the learning of "Understanding each other", teachers need to set up a dialogue scene between "Zhang Qing" and "Li Lin" to encourage students to practice oral English through different role plays when designing teaching plans for students, as as result, the students will be enabled to gradually improve the dialogue ability and language application ability. Besides, students are encouraged to continue writing training. In this process, teachers need to observe and evaluate the actual performance of students, and introduce the writing skills according to the creation style and direction of the article, or explain the knowledge points for students through micro lessons and videos, so that students can better master and use them. As micro-class teaching is a brand new application mode, in the process of implementing normal guidance and training, students should be assisted to master practical skills and gradually enhance their ability to learn and use, so as to maximize their ability to continue writing after reading.

\subsection{In-depth interpretation of the text content to cultivate students' thinking and consciousness of writing after reading}

From the perspective of interaction, it is very important to carry out the teaching activities of after-reading writing in senior high school English. During the process of guiding students to interact with texts, it is necessary to cultivate students' thinking of after-reading writing through different ways such as teacher-student interaction and student-student interaction. To be specific, teachers must introduce the teaching method of text analysis and interpretation to gradually cultivate and improve students' ability to continue writing after reading. For example, in the process of learning the article "The Universal Language", it is necessary to introduce different problems to students, such as letter problems and introductory style, so as to help students deeply analyze and accurately interpret the content. In addition, teachers need to determine the direction of writing after reading according to different design contents, and encourage students to continue writing by connecting classical culture and special scenic spots, so as to gradually cultivate their creative ability. During this period, teachers need 
to introduce different questions and guide students to make a simple overview of the writing style and storyline of the article, paving the way for the next step. This teaching method can enable students to quickly master some of the words in the article, and obtain emotional accumulation, so that students can gradually develop the habit of thinking after reading. And, the teacher can also through the Internet platform to collect some relevant model essay, lets the student in the case of imitating, clear written ideas and direction, and able to communicate with the original genre in-depth process, let the students grow 1, progressive transformation, and successfully complete the teacher to create the stepwise learning tasks, Make students not only master the language application ability, but also can be summarized in a classic case to read written law, thus enables the student to the text abstract knowledge visualization, visualization, make the whole teaching process more orderly and standardized, maximize, cultivate the students' written thinking and improve their comprehensive application ability indirectly. Teachers can also collect some model essays related to it through the Internet platform, so that students can clearly write ideas and directions under the condition of imitation. In addition, in the process of in-depth interaction with the original genre, students can master the knowledge from low level to advanced level, and the step learning tasks created by teachers can be completed successfully by students, so that students can not only master the application ability, but also they can be capable of summarizing the law of writing after reading after learning classic cases. Thus, the abstract understanding of the text can be visualized, and the whole teaching process can conducted in a more orderly and standardized manner, maximizing the effect of the cultivation of students in writing thinking for indirect improvement of ability in comprehensive application.

\section{Conclusion}

In conclusion, during English classroom teaching in high school, the traditional teaching shows non-obvious effect in cultivating and improving students' ability to write after reading. Through the analysis of the reasons, the general reason is that students failed to conduct accurate analysis on the text structure for master the text style and the lack of targeted reading follow-up guidance. After reading, students are demonstrated to be insufficient in writing and reading based thinking and skills. Based on this, teachers need to construct reading situations, implement hierarchical teaching, apply micro-lesson technology, strengthen text interpretation and other ways based on the interactive perspective in order to guide students to master the text structure, explore the text style for implementation of the targeted guidance and assistance, as a result, to promote students to gradually master the relevant skills, stimulate students' thinking and enthusiasm for writing after reading. The continuous optimization and improvement of classroom teaching quality can be enhanced.

\section{References}

[1] Tu Meimei. Design and practice of output-oriented teaching mode for senior high school english writing after reading[J]. English Teacher, 2021, 21(1): 5.

[2] Chen Yajun. Inspiration, sorting, imitation and creation -- The Practice of self-learning based teaching strategy of after-reading English writing in senior high school[J]. English Language Learning, 2020(7): 5.

[3] Sun Liang. Research on the application of reading follow-up in teaching of English writing in high school[J]. Seeking Knowledge Guide, 2020(50): 2.

[4] Chang Lili. Practice and Exploration of High school English writing after reading based on classroom teaching [J]. Good Day, 2021(15): 1.

[5] Li Yani, Zhang Yuan. A preliminary study on the teaching method of English writing after reading in high school based on the background of core literacy[J]. English Journal for Middle School Students, 2020(12): 14. 